\title{
LANGUAGE LABORATORIES IN UNIVERSITY TEACHING IN SWEDEN
}

with special reference to the work of the LLL Research Committee

In present day educational language the term "language laboratory" seems to be used to denote anything from a "mini-lab", consisting of a portable tape recorder with several sets of headphones, to highly sophisticated installations with full integration of sound and picture, often controlled by computers. As very few educationalists - and indeed very few producers of equipment and materials - seem willing to drop the magic word "laboratory", which obviously is thought to indicate a "scientific approach" to language instruction, we shall probably have to ask people to specify what they mean when speaking about "language laboratories" for quite some time.

\section{Terminology and definitions}

As early as in 1958, C. W. Brubaker suggested the term "learning center" for installations that offered an integrated presentation of audio and visual materials. He has also suggested the term "learning laboratory" for installations where the teaching machine has joined the audio and visual components. It follows that the degree of automation would be a decisive factor when distinguishing between "classrooms", "language laboratories", and "learning laboratories".

However, if we analyze what is going on in a "language laboratory", we shall soon find that it is not the degree of automation that distinguishes e.g. a "language laboratory" from an ordinary classroom (or from a "learning laboratory"). There is no intrinsic difference between an instructional method in which the teacher provides the necessary data, exercises the necessary control, and supplies additional information when and if needed, directly through his presence (in the classroom or in the "language laboratory") and an instructional method in which the teacher fulfills the same duties indirectly with the aid of preprogrammed machinery. Similarly, whether visual stimuli are presented to the students through the means of a video-tape recorder, individual projector or textbook makes no fundamental difference in the methodological approach used. Which method of presentation is chosen depends on purely external factors such as the number of teachers available, housing facilities, cost of equipment and materials.

"Paper read at the 10th FIPLV Congress in Zagreb, Yugoslavia, 5-9 April, 1968 
The basic difference between "classroom instruction" and "laboratory instruction" is that of group study versus individual study. The essence of "laboratory learning" is the individual work: the possibility for each student to work with materials designed to meet his individual needs at his own speed. It follows that a "language laboratory" (or indeed a "learning laboratory") is not a teacbing aid- it is a learning aid, a fact that is not always recognized, but which is of great importance when discussing the cost/efficiency problem.

If this definition of "laboratory work" is accepted, it also follows that the ordinary classroom can be used as what I should like to call a "learning laboratory", when the students are working with individual material (with or without the teacher acting as a supervisor). However, this is possible only with visual stimuli (in this case in the form of a textbook or written programme); the moment the audio component is introduced, nothing but group work is possible unless special equipment is used. With the modern emphasis on the spoken language, it is clearly not possible to do without the audio component; I should therefore like to suggest that a "laboratory" designed for language learning be called a "language learning laboratory".

For the purpose of this paper I shall distinguish between:

(1) classrooms, i.e. rooms used for group work without special audio equipment;

(2) audio-visual classrooms, i.e. rooms used for group work with special audio equipment;

(3) learning laboratories, i.e. rooms used for individual learning without special audio equipment (which thus may be an ordinary classroom used for individual study with visual stimuli only);

(4) language learning laboratories (LLL); i.e. rooms used for individual language learning with special audio equipment.

Activities and not equipment distinguish a classroom from a learning laboratory and an audio-visual classroom from a language learning laboratory. In many "language laboratories" central projection is used for some exercises. As central projection implies group work instead of individual study, such a "language laboratory" would partly be used as a language learning laboratory (without central projection) and partly as an audio-visual classroom (with central projection).

The size of the "laboratory" is irrelevant. A language learning laboratory may consist of one tape recorder used for individual study;, 
or it may consist of 500 tape recorders used for individual study. Similarly, it follows that the student's study-the place where his learning takes place- must be considered as a learning laboratory. If he then uses a special tape recorder, it may even be a language learning laboratory.

"Language laboratories" are sometimes divided into "student controlled language laboratories", i.e. individual tape recorders without connection to a central table operated by an instructor, and "teacher controlled language laboratories", i.e. the individual tape recorders are connected to a central table from which the instructor can control the students' work. Clearly there is no such thing as "student control". The student is either controlled by the programme he is using, or if this is not enough (which may be the case e.g. in pronunciation training), he is externally controlled by an instructor. This external control can be exercised either directly from the instructor's table, or indirectly' through some sort of machinery that has been pre-programmed by the course constructor. In both cases the student is, in fact, controlled by the teacher responsible for the construction of his course. I shall therefore distinguish between

(a) programme controlled laboratories, i.e. such (learning or language learning) laboratories where no control is exercised by an instructor being present either directly or indirectly, and where no special equipment for external control is used;

(b) externally controlled laboratories, i.e. such (learning or language learning) laboratories where an instructor is exercising control either directly or indirectly, and where special equipment is used for such controlling purposes.

It is obvious that an externally controlled laboratory can be used also as a programme controlled laboratory, while the opposite is not true, as the programme controlled laboratory lacks the special equipment necessary for external control.

Early Experiments with "language laboratories" at Swedish universities

Tape recorders were introduced in university teaching and learning in Sweden in 1951, when the Phonetic Training Laboratory was created at the University of Stockholm by the pioneer in this field in Sweden, Dr. Max Goroslch. The modern language departments of the university soon started using the facilities offered by Dr. Gorosch's laboratory, and the audio-visual classroom has been used by the universities since the early 1950's. The other Swedish universities had become interested in this work at an early stage and were, either independently 
or in collaboration with Dr. Gorosch, experimenting with tape recorders on an increasing scale. Of particular interest and importance are the experiments carried out in Lund by Professor Bertil Malmberg and in Goteborg by Dr. Svante Stubelius.

The first externally controlled language learning laboratory (LLL) was installed already in 1952 at the Phonetic Training Laboratory in Stockholm: four tape recorders for individual work were connected to a central table constructed and built at the Phonetic Training Laboratory. However, the student response to the facilities offered for individual learning, either in the form of programme controlled LLL or in the form of externally controlled LLL, was rather discouraging.

There was, of course, a general shortage of programmes. The "language laboratory" was considered particularly useful for pronunciation and intonation training, and a series of adaptations of foreign programmes was used with varying degrees of success. As many of the students had a fairly acceptable pronunciation and intonation of the language they were studying at their admittance to the universities, the LIL came to be regarded more as a place for "remedial training" than as an instrument for learning within the ordinary university curriculum. At the same time an acute shortage of lecture room and laboratory facilities, particularly in Stockholm, was becoming a strong negative factor. The first "professionally manufactured" LLI with external control of the students was installed in the cellar of the Arts Library of the University of Stockholm, and no student was likely to ever enter this stuffy room on his own accord.

\section{The Work of the Commission on University Teaching and Learning}

The structure of the Swedish universities was changed radically in 1959. An investigation by a Royal Commission had shown that less than $50 \%$ of the Arts students admitted to the universities left with an academic degree, and in many cases those eventually receiving their degrees had spent by far too much time at the university. The old lecture system was exchanged for a system with a strong emphasis on group and class work, and a new category of highly qualified university staff, universitetslektorer, ranking next to professors, was introduced to direct this work.

When the efficiency of this system was evaluated at the beginning of the 1960's, it was found that a greater percentage of the students left the universities with a degree; however, many students still spent by far too long on their undergraduate studies. To remedy this, a Commission on University Teaching and Learning was entrusted with the task of finding better instructional methods, and since then this com- 
mission has investigated a great number of vital problems. It may be noted that the Commission on University Teaching and Learning is composed solely of university staff; its members are recruited among the leading experts in the various fields being investigated.

In spite of great efforts on the part of the authorities and the universities, the time spent on first degree studies by the average modern language student was far beyond that recommended by the government. In early 1966, the Commission on University Teaching and Learning therefore decided to investigate the possibilities of an increased use of LLL in the university courses in modern languages in order to reduce the length of undergraduate study in modern languages. A sub-commission, the LLL Research Committee, was created, consisting of a central body including linguists and psychologists to direct the project, and regional sub-committees at the universities of Uppsala, Lund, Goteborg, and Stockholm.

The ultimate goal of the LLL Research Committee is to give recommendations on whether LLL should be integrated with other university instructional methods in modern languages; in other words, to assess the effects of LLL. It is obvious that the cost/efficiency ratio will play a major role in the final decision, but it was quite clear to the LLL Research Committee that no valid comparisons between the effects of LLL and other instructional methods could be made at this stage. Before doing this it would be necessary to investigate the LLL methodology in use and to find an acceptable methodology based on empirical facts. In this respect the policy of the LLL Research Committee is entirely different from that of other groups investigating the LLL in Sweden, e.g. the Board of Education.

The first task of the LLL Research Committee was to initiate the production of LLL programmes, which could later be used for methodological research purposes. In the academic year 1966/67 some 75 LLL programmes ${ }^{1}$ were produced in English, French, German and Russian, and the plans for this academic year include the production of another 150 LLL programmes. The programmes produced last year are now being revised on the basis of results reported from the various university departments taking part in the project, and these programmes will be used in their second or third version next academic year.

This production of LLL programmes has also stimulated the use of LLL in the regular university courses. On an average there has been

${ }^{1}$ irrespective of actual length a programme is considered to be 15 minutes. Thus, a programme of 30 minutes would be counted as 2 programmes. 
an increase in the use of LLL with $300 \%$ this year as compared with last year. This tendency can also be demonstrated in absolute figues: in the autumn of 1966 three externally controlled LLL at the University of Stockholm were used to about $50 \%$ of their capacity, while four externally controlled LLL were each used for more than 50 hours a week in the autumn of 1967, which made technical service and maintenance a very difficult problem. There are no figures on the use of programme controlled LLL for obvious reasons.

It is quite evident that LLL programmes and methodological approach are interrelated. The LLL Research Committee therefore envisages its future work as continuous research on the effects of the variables connected with language learning. It is also evident that one of the main difficulties is to find a research model which includes as many as possible of the relevant variables. To this end the Committee is now working on a tri-dimensional research model which includes a micro-analysis (in linguistic and psychological terms) of course aims, teacher and student behaviour in the LLL.

It would lead too far to discuss more than a few aspects of the work of the LLL Research Committee in this paper, and I shall therefore limit my discussion to a few points I find particularly interesting.

\section{The cost/efficiency problem}

Although the salesman may have a different view, no responsible educational authority would consider the installation of costly equipment just for the fun of it. The cost of the equipment and its maintenance must pay dividends in increased efficiency, which can be measured in financial terms through decreasing costs in other parts of the course expenditure. In other words, a given number of students should reach a given language proficiency either in a shorter time or with a smaller number of qualified instructors being involved (directly or indirectly) to make LLL worthwhile. When assessing possible savings, however, it is important to keep in mind that LLL are learning aids. It is not only a question of reducing the number of instructors or exchanging highly qualified instructors for LLL stewards, it is a question of assessing overall gains. Thus, the time the average student has to devote to learning the foreign language is an important factorif courses can be reduced from 18 months to 12 months through the use of LLL, there has indeed been a considerable gain from the point of view of national economy.

This is, of course, nothing new. There are, however, two points I should like to make. First I should like to agree with Elton Hocking in his statement that "language laboratories have not been given a fair 
tri:ll" (1) in the numerous comparative studies between "classroom learning" and "language laboratory learning" experienced classroom teachers, using well developed methods of demonstrated suitability for classroom use, have been compared with laboratory teachers using methods that may or may not be suitable for laboratory learning, and using materials that very seldom fulfill the requirements of language laboratory courses.

Most textbooks produced for school use now include what the authors label as "language laboratory materials": usually a few tapes, which consist of passages from the book recorded by native speakers and with a number of exercises that normally take place in the classroom. Although I do not say that such materials are without value, I like to agree with Ornstein and Lado in their plea for more methodological research in the field of language laboratory instruction (2); which we have found methods that take full advantage of the facilities offered by the LLL, comparisons with "ordinary classroom instruction" are futile. It is also important to keep an open mind to the methodological approach in general; unfortunately some of my compatriots have become what Valdman very aptly has labelled as "obsessed with structure" (3), particularly within the secondary education system and the teacher training colleges. However, this tendency has not so far affected the universities; we want to base our instruction on empirical data, not on more or less unfounded hypotheses of how the child learns his first or second language.

My second point is concerned with the equipment. There is a strong tendency for teachers to become servants of modern technology: complicated machinery of doubtful pedagogical value is given to the teachers in the hope that they will find also some pedagogical justification for the latest mechanical or electronic gadget. Many universities take great pride in owning advanced externally controlled LLL with extensive control functions centralized to the instructor's console. Such laboratories are expensive to buy; the number of sensitive components e.g. a great number of relays, make costly technical servicing necessary. There is a great danger in using such LLL for measuring the cost/ efficiency ratio, where the cardinal rule must be never to use more complicated equipment than necessary for the learning procedure in question. If, as often seems to be the case, such laboratories are used for programme controlled learning, we cannot expect to have a favourable cost/efficiency ratio. It is important to find also the optimal relation between method and equipment before we attempt to measure the cost/ efficiency ratio. 
But we should also look at the equipment from the point of view of the individual learner. It is a truism to say that different students have different learning habits: some students like to work at their desks, others prefer to lie down on a couch; some students like to smoke a pipe while studying, others want a cup of tea every 15 minutes. Yet, in the LLL we seem to assume that everybody should conform to some sort of universal pattern.

We know that seemingly trivial factors can have a strong motivating or repressive effect in this complicated process that we call "learning"-to what extent have we taken this into account when constructing our LLL? Have we made full use of the possibilities offered by remote control, for example would it prove a sound investment to exchange the present student booths for nice comfortable "listening cabins", allowing the student to study in the same way as in his private learning laboratory? Would we get a different result if we exchanged the heavy headset, which is irritating the women students because it destroys their expensive hair-do's, for some sort of loudspeaker? At the same time we are careful not to spend our money on unnecessary functions, we must not be af raid to arrange our equipment in such a way that we make the best possible use of the students' motivation and interest in learning.

Surely these are important questions. Surely more research is needed also on this aspect of LLL construction. W Within the Swedish universities we are not inclined to accept the LLL of today as a final version of a learning aid. Through research, analysis and observation we want to come to a conclusion on what we need to provide for optimal learning. Then, w'e shall ask the producers of LLL equipment to provide $u$ : with exactly the functions we have specified.

\section{When is external control necessary?}

It is generally accepted pedagogical principle that "the unsupervised student is not permitted to drill on utterances in which his ear cannot hear defects" (4). In other words, programme control must be replaced by external control when we reach the point where the student can no longer evaluate his responses to the stimuli given by the programme.

This point could be called the minimal distinctive linguistic difference. It is obvious this point varies from student to student; such factors as hearing defects or low intelligence would have a negative effect. It is also obvious that the minimal distinctive linguistic difference varies from one language to another, and that it is quite different when expressed in terms of structure and when expressed in terms of pronunciation and intonation. While the average student may not be able to 
distinguish between a dental and an alveolar $t$-sound, he would easily recognize that something is wrong if he did not put the finite verb at the end of a subordinate clause in German.

With an ever increasing number of students this is a very important problem from the point of view of cost/efficiency. Considerable sums of money could be spent on the production of a first rate programme if we could be assured that no further external control would be needed, while the use of LLL may be less rewarding if a high degree of external control has to be observed. Furthermore, if external control (i.e. not through computer) is used how many students could be controlled by one teacher at a time?

In a survey of the use of LLL in Europe in 1966, I found that group sizes for pronunciation exercises in externally controlled LLL varied from 9 to 30. Professor Elton Hocking, in investigating the average time spent on monitoring students at Purdue University, has found that one student is normally taking up an average 59 seconds of the instructor's time (including possible corrections and analysis of the student's error) per monitor each student. About 6 minutes if there are 10 students in the group, and only 2 minutes if there are 30 students in the group. This situation can also be expressed in the negative way: in groups of 30 the student will work unsupervised for 58 minutes per hour, i.e. in the latter case the student is practically working with programme control only. It follows that while there is a considerable difference between a group of 5 students and a group of 10 students in this respect-unsupervised 48 and 54 minutes per hour respectively - there is only a marginal difference between a group of 20 and a group of 30-unsupervised 57 and 58 minutes per hour respectively. From this point of view one might as well have groups of 60 students-. unsupervised 59 minutes per hour.

However, it is obvious that the monitoring is not evenly distributed in a normal group-from the results of a previous diagnostic test of judging from previous experience of the students' performance in the LLL the instructor will devote more time to students with a low discriminative ability. Two important factors need further investigation: (1) which physiological and psychological qualities make a student less able to discriminate, in other words, can we through a diagnostic test predict who will need more external control?, and (2) is it possible to avoid external control by special discrimination training prior to the LLL course? It is true that some experiments suggest that previous discrimination training is of great value, but it will be necessary to determine the critical point in relation to certain "types" of students. 
It is also evident that group size cannot be seen from the point of view of the students only. Even though the actual external control exercised per student may be only slightly more effective when the size of the group is 30 instead of 60 , the role of the teacher may well be an impossible one with 60 students working on individual programmes. Thus, the optimal group size does not only take the students' problems into account, it is also based on a careful investigation of the teacher's role.

It should be noted that only the control factor has been discussed. Before the instructor is dismissed for good, the problem with error must be solved as well. After having found that he cannot repeat the desired sound or the desired phrase in spite of several attempts, a student will need additional information on how he should go about to produce the desired response. It is evident that this information should be based on an analysis of this student's particular problem. However, in this case the student is controlled by his programme, and he decides for himself whether or not his response is acceptable. There is no risk in letting him work on his own until he decides that he wants some extra help, and using Professor Hocking's experience, one might then suggest that a capable instructor can deal with 60 requests for additional information per hour.

It should also be noted that the motivation factor has not been included in the discussion above. Our own experiments with externally controlled programmes in groups of different sizes suggest that even when there are no statistically significant differences in linguistic ability, considerable differences in motivation occur. The greater number of LLL programmes in a certain course, the more important it will be that the motivation factor is observed and kept at a high level.

It seems to us that all these questions demand a new and accurate description of what goes on in LLL. Our resources are therefore being concentrated on this problem: a study of programme, instructor and student interrelation in the LLL. 